\title{
La necesaria invención del sentido: de Si esto es un hombre a El hijo de Saúl
}

\author{
Mario AZNAR PÉREZ \\ Universidad Complutense de Madrid \\ Departamento de Filología Italiana \\ marioazn@ucm.es
}

\section{RESUMEN}

Este artículo plantea un estudio crítico del problema de la representación del horror extremo y, particularmente, del Holocausto nazi. El propósito de este análisis es ahondar en el tema -ya clásico aunque quizá hoy más vigente que nunca- de la inefabilidad del horror desde una perspectiva comparada e interdisciplinar, prestando especial atención a las posibilidades de transgredir el interdicto representativo de la Shoah y a las causas que animan esa hipotética necesidad de transgresión. Para ello nos hemos detenido en el análisis comparado de la obra Si esto es un hombre (1947), del escritor italiano Primo Levi, y del film El hijo de Saúl (2015), del director húngaro Lázsló Nemes.

Palabras clave: representación, Shoah, literatura, cine, Si esto es un hombre, El hijo de Saúl.

\section{The Necessary Invention of Sense: from If This Is a Man to Son of Saul}

\begin{abstract}
This paper presents a critical study of the problem of the representation of extreme horror and particularly the Nazi Holocaust. The purpose of this analysis is inquire into the classic -and perhaps even more relevant today than ever- subject of the ineffability of horror from a comparative and interdisciplinary perspective, with particular attention to the possibilities of transgressing the representative interdict of the Shoah and the causes that encourage this hypothetical need for transgression. To do this we have focused in the comparative analysis of the work If This Is a Man (1947) by the Italian writer Primo Levi, and the film Son of Saul (2015) by the Hungarian director Lázsló Nemes.
\end{abstract}

Keywords: representation, Shoah, literature, cinema, If This is a Man, Son of Saul. 


\section{Introducción}

La quinta acepción que el Diccionario de la Real Academia Española propone para el término «guerra» hace referencia a la «oposición de una cosa con otra». Si nos detenemos a reflexionar sobre este enunciado, pronto descubrimos que, más allá de su incuestionable verdad, esta resulta ser una definición demasiado simplista, pues reduce a solo dos los términos del enfrentamiento. La realidad, mucho más ambigua y escurridiza de lo que las formas del lenguaje son capaces de abarcar, excede con creces las ambiciones de cualquier diccionario, y la Historia -militarnos enseña que las fuerzas que entran en juego en un conflicto bélico son múltiples y difíciles de determinar. Tanto, que detrás de la etiqueta «conflicto socio-político» podemos identificar una suerte de prisma óptico capaz de refractar y descomponer hasta el más nítido de los componentes que forman parte de una guerra.

Sin duda, entre todos los elementos que podrían configurar una definición idealmente completa del término «guerra», el horror ocupa un lugar fundamental. Horror relacionado con la fuerte intensidad de un sentimiento desagradable, con la desmesura de un acto violento o cruel, con el exceso de maldad. En cualquier caso, el horror mantiene vínculos con lo extraordinariamente grande y desproporcionado, con lo que no pueden abarcar la razón ni los sentidos, con lo sublime negativo, con aquello ante lo cual la forma resulta precaria e insuficiente. Ante este fenómeno, la estética y las teorías del arte y de la literatura nos invitan a estudiar algunas de las posibilidades que el arte plantea como forma de representar el horror de la guerra.

El escritor chileno Roberto Bolaño sugirió que el crimen es «el símbolo del siglo XX» (Bolaño 2004: 206), mientras que Frigolé Reixach (2009: 8) ha señalado directamente que el siglo XX es «el siglo del genocidio». Ambas afirmaciones coinciden en destacar que nuestra historia más reciente está marcada por la violencia y el horror, es decir, por dos de los rasgos fundamentales de lo que bien puede considerarse el hecho histórico más destacado y deplorable de los últimos cien años: la Shoah u Holocausto judío perpetrado a manos del régimen nazi ${ }^{1}$. Cuando hablamos de Shoah («catástrofe», en hebreo), nos referimos al asesinato masivo y sistemático de los aproximadamente seis millones de judíos europeos que fueron exterminados bajo el mando de Adolf Hitler y sus colaboradores durante la Segunda Guerra Mundial.

Aunque hoy en día estemos ya familiarizados con la palabra «genocidio», cabe destacar que fue el jurista judeo-polaco Raphäel Lemkin quien acuñó el término en 1944 tras huir a Estados Unidos de la persecución nazi. Lemkin es conocido también por ser el principal impulsor de su inclusión como delito en el Derecho Internacional, definiendo el genocidio como «[...] un plan coordinado de diferentes acciones que pretende la destrucción de las bases esenciales de la vida de grupos nacionales con el fin de aniquilarlos» (Lemkin 1944: 79-95). Esta definición engloba ya el fundamento de esa experiencia desbordante del horror extremo que provo-

\footnotetext{
${ }^{1}$ Ya antes de la Segunda Guerra Mundial, el mismo Winston Churchill (2015) usó la expresión holocaust para referirse al genocidio armenio que tuvo lugar en Turquía entre los años 1915 y 1923. 
ca su propia irrepresentabilidad, y demuestra que la palabra «genocidio» no alude a una simple matanza de las que están repletos los anales de nuestra Historia, sino que se refiere a un fenómeno criminal de particulares dimensiones.

Atendiendo a las palabras de Lemkin, vemos cómo el crimen genocida implica premeditación y racionalidad en el acto mismo de la coordinación, al tiempo que destaca la insondable intensidad del fin que lo mueve: «la destrucción de las bases esenciales de la vida», que en el caso concreto del genocidio judío se tradujo en casos masivos de infanticidio y esterilización o asesinato de mujeres. ¿Cómo puede un ser humano hacer derivar de un «conflicto socio-político» un proyecto de exterminio racial conocido técnicamente como «solución final (Endlösung) de la cuestión judía»? ¿Cómo puede otro ser humano tratar de representar artísticamente un fenómeno de tal magnitud?

\section{Escribir la experiencia-límite}

Como sabemos, es ya un tópico intelectual hablar de los límites del lenguaje en relación con la experiencia del horror $\mathrm{y}$, más concretamente, con la experiencia de la Shoah. Como consecuencia de esta presunta limitación, se ha señalado incluso la imposibilidad de hacer arte de cualquier tipo en torno al tema de los genocidios - no solo el perpetrado bajo el amparo ideológico del $\mathrm{Nazismo}^{2}-\mathrm{o}$ de cualquier otra forma de violencia y de crueldad extrema. Pensemos en la socorrida prescripción de Theodor W. Adorno: «Escribir un poema después de Auschwitz es un acto de barbarie» (Adorno 2008: 25). Sin embargo, esta sentencia, pronunciada por uno de los máximos representantes de la Escuela de Fráncfort, debe ser interpretada dentro de un contexto en el que el arte permanece, pero es ya imposible -o barbárico- tratar de devolverle el estatus que poseía antes de la Guerra, o siquiera intentar recomponer los fragmentos que de él han hecho la experiencia del genocidio y el consiguiente fracaso de la racionalidad occidental. Por el contrario, Adorno sitúa las posibilidades de la poesía en la mirada constante del poeta hacia lo sucedido -el exterminio de millones de seres humanos- por lo que primero resulta necesario identificar qué entiende el filósofo por poesía, y luego dilucidar qué tipo de poesía es la que ha dejado de poder escribirse ${ }^{3}$. El escritor Günter Grass, en su libro Escribir después de Auschwitz, demuestra haber entendido la sentencia adorniana como algo que «se interponía en el camino de la fe en el futuro» (Grass 1999: 19). Esta forma -errónea, podemos decir ahora- de entender el dictum de Adorno, implica una lectura censora de sus palabras y llega hasta nuestros días en forma de una polémica que

2 También los más recientes genocidios de Ruanda (1994) o de Srebrenica (1995).

${ }^{3}$ Como bien ha señalado José Antonio Fernández López: «Los poetas estudiados y admirados por Adorno fueron George, Hofmannsthal, Borchardt, Eichendorf, Mörike o Heine. Si exceptuamos a éste último, el resto podrían integrarse en una amplia tradición poética germánica de corte 'conservador', un canon poético en plena consonancia con la corriente formativa burguesa de la Bildung. Es esta tradición la que no puede continuar sin más, como si nada hubiera ocurrido y es, por lo tanto, bárbaro escribir poesía después de Auschwitz como ‘las de antes'» (Fernández López 2006: 3). 
mezcla argumentos éticos y estéticos. Lo que en su momento fue entendido como una prohibición, hoy puede ser leído como una advertencia ante la incompatibilidad entre las formas tradicionales y la representación artística de la catástrofe europea ${ }^{4}$.

Si siguiendo la idea de Adorno descartamos, en un primer lugar, aquellas formas de creación artística que buscan retomar su estado anterior al Holocausto, podemos identificar tres tipos principales de creación artística: aquellas centradas en la Shoah con intencionalidad estrictamente estética, aquellas que lo hacen con intencionalidad anamnética y aquellas que lo hacen con ambos fines. Estas últimas, a nuestro parecer, son las más interesantes. Pero aún debe señalarse otra distinción importante: la que separa a los autores supervivientes de la experiencia-límite que supuso el Holocausto, de aquellos otros autores distantes al drama. En el primer grupo se sitúan los narradores-testigos cuya legitimad y autenticidad es comúnmente aceptada, es decir, aquellos autores «canónicos» como Imre Kertézs, Jean Améry, Elie Wiesel, Filip Müller o Primo Levi, del que hablaremos más adelante. En el otro grupo se agolpan infinidad de creadores que con mayor o menor fortuna y con mayor o menor rigor han tratado de representar el horror de los campos de exterminio y de sus consecuencias históricas sin haber sido directamente partícipes del evento. Entre ellos se encuentran los novelistas W. G. Sebald y Demetrio Paolin, o el cineasta Lázsló Nemes, sobre cuya obra El hijo de Saúl (2015) nos detendremos también a continuación ${ }^{5}$.

Todas estas contraposiciones encierran una doble manera de entender los límites de la representación del horror extremo que se vivió en campos de exterminio como el de Auschwitz o el de Treblinka. Por un lado, estas limitaciones pueden entenderse como limitaciones estéticas o formales, es decir, considerando la insalvable irreductibilidad de un fenómeno de tal magnitud a través de la forma, ya sea literaria o visual. Por otro, pueden ser entendidas como limitaciones éticas relacionadas con el grado de legitimidad con que alguien ajeno a la experiencia de los hechos puede tratar de revivir o de reconstruir esos mismos hechos. Entonces, ¿no se puede representar el horror de la Shoah, o no se debe representar el horror de la Shoah? ¿El problema de una novela o de una película sobre el Holocausto destinada al entretenimiento de un público de masas es un problema ético o estético? Estas son, sin duda, cuestiones difíciles de responder. Sin embargo, no podemos obviar la vigencia de este tema como fuente de inspiración creativa, ni la ingente cantidad de obras que cada año aparecen para aportar una nueva mirada sobre la figura poliédrica del genocidio (Burucúa y Kwiatkowski 2015).

${ }^{4}$ «El arte es imprescindible, pero Auschwitz, a su vez, condiciona la expresión estética, forzándola hasta los límites de su propia capacidad representativa de modo que sea obligada a pensar y articular su propia imposibilidad» (Fernández López 2006: 4).

${ }^{5}$ Un caso extraordinario que podríamos situar en un lugar intermedio es el del libro Anotaciones de Jakob Littner desde un agujero bajo tierra (1948), de Wolfgang Koeppen. En este caso nos encontramos ante un testimonio directo, el del comerciante judío Jakob Littner, cuyas anotaciones reales han pasado por el tamiz literario del escritor Wolfgang Koeppen. 


\section{La deriva de una prohibición cultural}

Aunque aparentemente la dilucidación del problema ético de la representación del Holocausto escapa a los objetivos y al marco de este artículo, ambas perspectivas -ética y estética- son aquí indisolubles. En un texto de 1978 aparecido en The New York Times 6 , el escritor y superviviente Elie Wiesel advierte: «The Holocaust must be remembered but not as a show». De este modo, Wiesel pone el acento del problema sobre la pareja conmemoración-trivialización, que tan difícil de separar resulta cuando entramos en el ámbito de la ficción. Como manda la convención, existen temas «serios» y formas «serias». Los temas de la muerte y el crimen son los temas «serios» por excelencia, mientras que formas «serias» de representación serían el testimonio y el documental ${ }^{7}$ (nunca una novela, nunca un telefilm). Sin embargo, en las últimas décadas el tema del genocidio ha encontrado acogida en formas que la tradición considera menores, como son el cómic o la novela gráfica con Maus (1980), de Art Spiegelman, o el cine cómico con La vida es bella (1997), de Roberto Benigni ${ }^{8}$.

Como ya hemos señalado, el fenómeno del Holocausto es sublime en el sentido de excesivo e inabarcable, y ante esto toda forma resulta limitada e insuficiente. El lenguaje verbal con el que se construye la literatura encuentra su particular limitación en la obligada construcción secuencial, sintáctica, lógica ${ }^{9}$. Por el contrario, la idea de que la imagen puede representar un fenómeno complejo apuntando al mismo tiempo hacia varias de sus facetas es mucho más verosímil. A favor de esta idea, Anton Kaes (Kaes 1992: 208) ha destacado las posibilidades del cine como arte sincrético que aúna elementos de la literatura, la pintura, el teatro, la música y la fotografía, frente a las limitaciones inherentes a la lógica de la descripción historiográfica y de la narración literaria. Ahora bien, Álex Vicente, quien considera que el debate sobre Arte y Holocausto ha sido ya superado, aún se cuestiona: «¿Qué puede hacer el cine, en un marco documental o de ficción, para reproducir un fenómeno que no se puede filmar, del que no existen imágenes de archivo ni testimonios legítimos $[\ldots]$ y cuya reconstrucción es percibida por muchos como moralmente abusiva?» (2016). Sobre la posibilidad y la legitimidad de recrear el sufrimiento de los prisioneros y los lugares en que tuvo lugar el Holocausto, Claude Lanzmann, director de Shoah (1985), publicó un artículo en Le Monde titulado «Holocauste, la réprésentation imposible» (1994), situándose en el extremo opuesto a la postura de un director como Benigni, al defender que es solo la voz de los testigos experienciales

6 «The Trivialization of the Holocaust: Semi-Fact and Semi-Fiction».

7 Además de Shoah (1985), el célebre documental de Claude Lanzmann, consideramos importante destacar el cortometraje documental de Alan Resnais Noche y niebla, de 1955.

8 Sobre otros casos de horror extremo podemos destacar, incluso, filmes de animación tan premiados como Vals con Bashir (2008), sobre la matanza de refugiados palestinos en Líbano en 1982, o la más reciente La imagen perdida (2013), de Rithy Panh, que representa las matanzas que tuvieron lugar durante el régimen comunista de Pol Pot en Camboya usando figuras de plastilina y dioramas.

${ }_{9}$ Como el tacto, el habla y la escritura no pueden prescindir de la linealidad (aunque esta, en algunos casos, pueda ser múltiple, pero nunca simultánea). 
-como sucede en su documental- la que puede evocar el horror de lo sucedido. A lo largo de los años, sin embargo, este precepto ha sido desobedecido en innumerables ocasiones, y la lista de filmes de ficción sobre el Holocausto va de Kapó (1960), del italiano Gillo Pontecorvo, a la célebre La Lista de Schindler (1993), del director estadounidense Steven Spielberg, entre otros muchos.

El debate sobre la posibilidad de representar la Shoah discurre por algunos puntos clave que merecen ser destacados. Por un lado, el citado conflicto entre la conmemoración y la trivialización de los hechos, esto es, alimentar la perseverancia del recuerdo sin vaciar de sentido los acontecimientos reales. Por otro lado, y en estrecha relación con el punto anterior, la preocupación ante una posible «instrumentalización» del Holocausto, la cual implica que la representación de la catástrofe deja de ser un fin en sí misma y se convierte en un medio para transmitir otros mensajes o representar otras realidades relacionadas con la política, la moral o el mero entretenimiento. Y, por último, cabría destacar que muchos pensadores y creadores han centrado el debate sobre el aspecto de la «recreación», preguntándose si es legítimo inventar el dolor ajeno cuando este excede todas las dimensiones previamente conocidas.

Los dos primeros aspectos se topan con el muro del perspectivismo, ya que a pesar de las aspiraciones generalmente totalizadoras de las representaciones del Holocausto, resulta inevitable transitar el terreno de la interpretación histórica ${ }^{10}$. Desde este punto de vista, el problema de la objetividad se resuelve apelando a su imposibilidad. En cuanto al problema de la recreación, el debate se intensifica principalmente por la falta de referentes. Como es sabido, las filmaciones estaban terminantemente prohibidas dentro de los campos de concentración nazis, también entre los miembros de las SS. Por supuesto, los prisioneros tampoco podían disponer de cámaras fotográficas, aunque sí disponemos de algunas instantáneas tomadas de forma furtiva ${ }^{11}$. Esto nos lleva a confirmar que la mayoría de referentes disponibles son testimonios escritos y orales de prisioneros supervivientes, por lo que cualquier representación que se base en ellos cuenta de entrada con las limitaciones del lenguaje verbal experimentadas ya por los testigos directos ${ }^{12}$.

A esta ausencia de testimonios visuales sobre los que basar las representaciones hay que añadir una nueva vía de discusión que resulta fundamental en nuestros días: ¿cómo escribir sobre las deportaciones y los campos de concentración ahora que los testigos están desapareciendo? Cuando han pasado más de setenta años desde la

10 En este sentido, y a propósito de La lista de Schindler, Alejandro Baer señala que todo «relato cinematográfico implica una perspectiva sobre la historia, una propuesta de identificación a la audiencia, así como un conjunconjunto de significados adheridos al relato en forma de enseñanzas o lecciones". (Levi 2006: 10)

11 Son célebres las cuatro fotografías tomadas por Álex, miembro de un Sonderkommando, durante el mes de agosto de 1944 en el campo de concentración de Auschwitz. La aparición de estas imágenes, que retratan a otros miembros del Sonderkommando encendiendo una pira con los cuerpos desnudos y amontonados de otros prisioneros, reavivó el debate sobre la representación de la Shoah. Sobre estas imágenes y sobre sus posibilidades representativas escribió Georges Didi-Huberman su ensayo Imágenes a pesar de todo (2003).

12 Estaríamos hablando, pues, de representaciones hechas a partir de otras representaciones. 
liberación del campo de concentración de Auschwitz, la polémica sigue viva, las representaciones literarias y cinematográficas siguen proliferando y El hijo de Saúl puede servirnos para medir el estado actual de un debate que nos concierne a todos.

\section{De Si esto es un hombre a El hijo de Saúl}

Primo Levi sobrevivió al campo de trabajo de Monowitz ${ }^{13}$. Allí, siendo todavía prisionero, comenzó a esbozar las primeras notas de lo que poco después se convertiría en uno de los más importantes testimonios sobre la experiencia del Holocausto. Publicado originalmente en 1947, Si esto es un hombre es considerado una de las representaciones canónicas del funcionamiento de los campos de concentración creados y gestionados por el régimen nazi. Si nos atenemos a la breve clasificación expuesta anteriormente, Levi ocuparía un puesto de relevancia en el grupo de esos narradores-testigos cuyas obras son consideradas imprescindibles para tratar de entender el porqué y el cómo del Holocausto, mientras que el cineasta húngaro Lázlò Nemes formaría parte de ese otro grupo en el que se hayan quienes no han sido testigos directos del evento, pero que aún así tratan de transgredir el célebre interdicto cultural.

El libro de Levi está estructurado en diecisiete capítulos de carácter fragmentario, que el mismo autor admite haber escrito «no en sucesión lógica, sino por orden de urgencia ${ }^{14}$ (Levi 2014: 4). Sin embargo, un gran arco cronológico recorre estos fragmentos y dota al texto de una ordenación implícita que va desde su detención en Italia a manos de la milicia fascista el 13 de diciembre de 1943, hasta la liberación de Auschwitz por el Ejército Soviético el día 27 de enero de 1945. Entre estas dos fechas discurre el testimonio de Levi, cuya narración, extraordinariamente objetiva, deja en un segundo plano las emociones privilegiando una mirada analítica sobre el funcionamiento interno del campo, su minucioso reglamento, sus regímenes de trabajo, las relaciones comerciales entre los prisioneros y los civiles que trabajaban con ellos en la fábrica de Buna, y la implacable jerarquización de los prisioneros según los motivos de su detención, su nacionalidad, su antigüedad en el campo e, incluso, la robustez de su físico.

Como sabemos, las motivaciones del libro no son solo de tipo personal, pues surgen de la necesidad de dar a conocer a los demás una realidad extrema ${ }^{15}$. De una parte, hay una urgencia por compartir con los demás el peso excesivo de la experiencia. Pero también hay una intención de denuncia y de acusación, una necesidad informativa, una advertencia: «La historia de los campos de exterminio debería ser entendida por todos como una siniestra señal de peligro» (Levi 2014: 1). Tiempo des-

13 Auschwitz III-Monowitz fue uno de los varios campos de concentración y exterminio que conformaban el complejo de Auschwitz, situado en los territorios polacos ocupados durante la Segunda Guerra Mundial.

14 Traducción propia.

15 En la breve introducción del libro, Levi declara que: «La necesidad de contar a los 'otros', de hacer a los 'otros' partícipes, había asumido entre nosotros, antes y después de la liberación, el carácter de un impulso inmediato y violento, hasta el punto de rivalizar con las demás necesidades elementales: el libro ha sido escrito para satisfacer esta necesidad» (Levi 2014: 3-4). 
pués de la liberación y del final de la Guerra, Levi aún advierte del peligro legando al lector un testimonio de corte casi jurídico. Las descripciones y el análisis sistemático de las distintas situaciones que se suceden a lo largo del relato conmueven por su falta aparente de rabia, de odio, de pasión. Donde uno esperaría una proclama a favor del castigo, encuentra una fotografía panorámica de la incomprensión y la intolerancia extremas. Como ejemplo, bástenos referir el viaje de Levi a Auschwitz -un «viaje hacia la nada, hacia abajo, hacia el fondo» (Levi 2014: 9)- durante el cual los prisioneros reciben los primeros golpes de los soldados alemanes que los escoltan: «la cosa fue tan nueva e insensata que no sentimos dolor, ni en el cuerpo ni en el alma. Solamente un estupor profundo: ¿cómo se puede golpear a un hombre sin cólera?» (Levi 2014: 9). Bajo la fórmula de esta sencilla pregunta se esconde el núcleo de la obra: la profunda impresión del narrador ante la falta de pasión y de emociones - de humanidad- y el exceso de lógica. Una impresión que Levi mimetiza y traslada al plano lingüístico del texto evitando prácticamente cualquier concesión al sentimentalismo, y utilizando un estilo objetivo y un lenguaje preciso que solo en determinadas ocasiones se permite jugar con la metáfora y la reflexión metafísica.

Incluso ante la «danza de los hombres apagados» (Levi 2014: 44), ante aquellos moribundos a quienes los mismos prisioneros llaman «Muselmänner» ${ }^{16}$ y que no tienen historia porque no sobrevivieron, Levi mantiene el estilo sobrio y directo de su narración. Así da cuenta Levi del proceso de deshumanización sufrido por los judíos en los campos de concentración, limitándose siempre a las experiencias vividas por él mismo, evitando la indagación psicológica de aquellos personajes a los que no trató de forma cercana, y renunciando a describir espacios y situaciones que él mismo no conoció (el crematorio o las cámaras de gas, por ejemplo). Este rigor testimonial imprime al texto una veracidad inaudita, al mismo tiempo que revela su inevitable parcialidad. Una imparcialidad en la que confluyen el testimonio de Levi y el largometraje de ficción de Nemes.

El hijo de Saúl es un film muy consciente de sí mismo, que conoce la polémica y el elenco de representaciones de la Shoah que lo preceden, pero que, sin embargo, se embarca en la aventura y asume todos los retos de la empresa. Por un lado, Nemes obvia la prohibición de «recrear»y ofrece imágenes de espacios que simbolizan el centro del debate, como son las cámaras de gas. Por otro, asume como eje central la parcialidad de su perspectiva, limitando la narración al entorno de un limitado grupo de prisioneros -un Sonderkommando de Auschwitz ${ }^{17}$ - y muy particularmente a un perso-

16 Los «musulmanes» son «i sommersi», los hundidos, quienes alimentan una nueva descripción infernal que, como las imágenes de El hijo de Saúl, entronca con la serie histórica que va de Dante a Francis Ford Coppola, pasando por El Bosco, Beccafumi, Rubens, Milton y Conrad (Burrucúa 2016). «Ellos pueblan mi memoria con su presencia sin rostro, y si pudiese encerrar en una imagen todo el mal de nuestro tiempo, elegiría esta imagen, que me es familiar: un hombre descarnado, con la frente baja y los hombros curvos, sobre cuyo rostro y en cuyos ojos no se pueda leer huella alguna de pensamiento» (Levi 2014: 86).

17 Los Sonderkommando («comandos especiales») eran grupos de trabajo formados por prisioneros judíos -y no solo- encargados de trabajar en las cámaras de gas y en los crematorios, desnudando a los prisioneros, desinfectando las cámaras, trasladando los cadáveres, etc. 
naje, Saúl, que como última muestra de humanidad se empeña en salvar del crematorio el cuerpo de un niño al que de forma deliberadamente ambigua toma por hijo suyo.

Si bien estos dos autores representan dos categorías muy bien diferenciadas, ambas creaciones comparten aspectos formales y argumentales, de entre los que hay que destacar la consciente elección de una perspectiva limitada, la renuncia a apelar al sentimentalismo y la reflexión metacrítica sobre el problema de la representación. Nemes, concretamente, fija la cámara en un primer plano constante del protagonista, ya sea de frente o de espaldas, dejando el terror del campo en un segundo plano al que la visión del espectador pocas veces accede. Se evitan así las imágenes panorámicas y el ambiente se reconstruye principalmente a través del sonido, no de la imagen ${ }^{18}$. De esta manera el horror de Auschwitz se oye y casi se huele, pero no se ve, lo que nos hace pensar en una translación al plano visual de los límites del lenguaje padecidos en el plano literario.

Primo Levi destaca la importancia de la confusio linguarum babélica que se vive en el campo, la incomunicación con el exterior, el mutismo impuesto a los prisioneros, el desconocimiento del alemán como lengua franca, la importancia de la música popular alemana que sustituye los mensajes verbales y marca el ritmo del trabajo diario, o la distancia abismal que separa el significado de palabras como «hambre» dentro y fuera del campo. Nemes, por su parte, no solo recoge todas estas manifestaciones del silencio y de la incomunicación -incluidas las órdenes en alemán que los nazis vociferan y que el film reproduce de fondo, sin traducir, incompresiblessino que hace consciente al espectador de que la imagen tampoco basta, de que ser testigo directo ocular tampoco es suficiente.

\section{Algunas cuestiones a modo de conclusión}

Como hemos visto, obras como Si esto es un hombre o El hijo de Saúl responden a la necesidad de mantener viva la memoria del Holocausto, y lo hacen incluyendo en su seno referencias explícitas a las dificultades y limitaciones que el acto de representar conlleva. A pesar de todos estos obstáculos, a lo largo de los años la literatura y el cine no han cesado en su empeño, y cada vez son más las obras que abordan la representación de las masacres humanas haciendo frente al desafío estético del horror. La pregunta, muchas veces formulada en estos términos: ¿puede el lenguaje -racional-representar un fenómeno radicalmente irracional?, habría de ser actualizada para poder abordar con rigor la posible transgresión de lo que durante mucho tiempo ha supuesto una prohibición cultural. En primer lugar, cuestionando la supuesta irracionalidad de la guerra y, en segundo lugar, replanteando la legitimidad ética de la representación artística del horror.

Cabe pensar, asimismo, que toda esta producción artística responde en cierta medida a la necesidad de dotar de sentido a un espacio de nuestra historia que toda-

${ }^{18}$ El encuadre restringido y el plano muy cercano demuestran cómo Nemes busca mostrar, pero no exhibir, lo sucedido. 
vía permanece silenciado ${ }^{19}$. Según esta hipótesis, tanto el arte de la escritura como el de la imagen buscarían inventar, mediante narraciones, el sentido del que la experiencia del Holocausto carece. Si no hay testimonios objetivos del genocidio no hay referentes fidedignos, por tanto la representación es siempre ficticia e imaginativa, siempre insatisfactoria, siempre en construcción. Memoria, lenguaje y ficción son conceptos que se imbrican en este intento por actualizar la cuestión del horror indecible e indescriptible, de tal modo que, desarrollada desde la perspectiva estética contemporánea, la pregunta se reconfigura: ¿puede una representación sin referente ser una representación? ¿Puede el arte contemporáneo inventar un sentido satisfactorio? ¿Puede darse por superado el desafío?

\section{Referencias bibliográficas}

Adorno, Theodor W. (2008): Crítica de la cultura y sociedad I. Prismas; Sin imagen directriz. Obra completa, 10/1. Madrid: Akal.

BAER, Alejandro (2006): «Auschwitz en el cine y la televisión» [en línea], en Holocausto: recuerdo $y$ representación. Madrid: Losada. En http://proyectos.cchs.csic.es/sscv/sites/default/files/cine.pdf [Consulta: 20/05/2016].

BolaÑo, Roberto (2004): Entre paréntesis. Barcelona: Anagrama.

BURUCÚA, José Emilio y KWIATKOWSKI, Nicolás (2015): «Cómo sucedieron estas cosas». Representar masacres y genocidios. Argentina: Katz.

ChurchiLl, Winston S. (2015): The World Crisis. Vol IV. The Aftermath 1918-1928. New York. Bloomsbury Revelations.

Didi-Huberman, Georges (2003): Imágenes a pesar de todo. Barcelona: Paidós.

FRIGOLÉ REIXACH, Joan (2009): Cultura y genocidio. Barcelona: Universitat de Barcelona. GRASS, Günter (1999): Escribir después de Auschwitz. Barcelona: Paidós.

KAES, Anton (1992): «Holocaust and the End of History», en S. Friedlandr (ed.): Probing the Limits of Representation. Nazism and the «Final Solution». Harvard: Harvard University Press.

LANZMANN, Claude (1994): «Holocauste, la réprésentation imposible», en Le Monde, 3 de marzo de 1994.

LEMKIN, Raphael (1944): El dominio del eje sobre la Europa ocupada: Leyes de la ocupación - Análisis sobre el gobierno - Propuestas para la enmienda. Washington: Fundación Carnegie para la Paz Internacional.

Levi, Primo (2014): Se questo è un uomo. Torino: Einaudi.

LÓPEZ FERNÁNDEZ, José Antonio (2006): «En los límites de lo indecible. Representación artística y catástrofe». A Parte Rei. Revista de filosofía 48, Noviembre 2006, pp. 1-12.

19 «Ésta, de la que hemos dicho y diremos, es la vida ambigua del Lager. De esta forma dura, apretados en el fondo, han vivido muchos hombres de nuestros días, pero cada uno por un tiempo relativamente breve; por lo que quizá se nos podrá preguntar [...] si es bueno que de esta excepcional condición humana permanezca algún recuerdo. A esta pregunta nos vemos tentados de responder afirmativamente. De hecho, nosotros estamos convencidos de que ninguna experiencia humana está vacía de sentido o es indigna de análisis» (Levi 2014: 83). 
Vicente, Álex (2016): «Historia de una polémica» [en línea]. El País. http://cultura.elpais.com/cultura/2016/01/08/actualidad/1452266477_763745.html [Consulta: $10 / 01 / 2016]$.

WIESEL, Elie (1978): «The Trivialization of the Holocaust: Semi-Fact and Semi-Fiction» [en línea]. The New York Times, 16 de abril de 1978 http://archives.chicagotribune.com/ 1978/04/19/page/32/article/trivializing-the-holocaust-semifact-and-semifiction\#text [Consulta: 10/06/2016]. 